\title{
Eficacia del rastreo cáncer prostático y su mortalidad en EEUU
}

Efficacy of screening on prostatic cancer and it's mortality in EEUU

Andriole G. y col N Engl J Med 2009; 360:1310-9.

\section{Objetivo}

Evaluar el efecto del rastreo del cáncer prostático sobre la mortalidad asociada a esta causa.

\section{Diseño}

Ensayo clínico aleatorizado multicéntrico.

Lugar

Participaron diez centros en EE.UU desde 1993, con.

\section{Población}

Fueron incluidos 76.963 varones de 55 a 74 años de edad que no tenían antecedentes de cáncer prostático, pulmonar, colorrectal u ovárico (las iniciales en inglés del acrónimo PLCO) y que no se hubieran hecho determinaciones de antígeno prostático específico (sigla en inglés PSA).

Desde 1995 también fueron excluidos quienes contaran con más de una determinación previa de PSA en los últimos tres años.

\section{Intervención}

Rastreo de cáncer prostático utilizando la combinación de la determinación en el suero del PSA durante los primeros seis años, y tacto rectal durante los primeros cuatro años; ambos con un intervalo anual.

Fue considerado anormal a un resultado con valores mayores a $4 \mathrm{ng} / \mathrm{mL}$ para el PSA y a la presencia de nodularidad, induración o asimetría de la próstata para el tacto rectal.

Los resultados anormales fueron informados a los médicos a cargo del paciente, y su manejo quedó a decisión de los mismos. Se tuvo en cuenta la contaminación del grupo control -indivi- duos que habian sido asignados en forma aleatoria a no recibir rastreo pero terminaron sometiéndose al mismo- realizando encuestas aleatorias anuales o bianuales en las que se inquirió sobre el rastreo de cáncer prostático mediante la determinación aislada o repetida de PSA.

Medición de resultados principales

El resultado principal se definió como la mortalidad asociada al cáncer de próstata.

Se realizaron análisis intermedios y las causas de muerte se obtuvieron a través de encuestas anuales a los participantes así como de la revisión de registros poblacionales y de historias clínicas.

El análisis se realizó por "intención de rastrear".

\section{Resultados principales}

La mediana del seguimiento fue de 11,5 años (con un rango de 7,2 a 14,8) en ambos grupos.

La adherencia al rastreo fue del $85 \%$ para la realización de PSA y del $86 \%$ para el tacto rectal.

La contaminación en el grupo control osciló entre el 40 y el $52 \%$ para la determinación de PSA y entre el 41 y el $46 \%$ para el tacto rectal.

No se encontraron diferencias importantes en el estadio tumoral y puntaje de Gleason entre los casos detectados en ambos grupos; mientras que la distribución de los tratamientos asignados a estos pacientes también fue similar.

La tabla 1 refleja los principales datos relacionados con la detección y la mortalidad por cáncer prostático.

Tabla 1: mortalidad y detección de cáncer prostático de acuerdo a haber sido sometido o no a rastreo del mismo.

\begin{tabular}{|c|c|c|c|c|c|c|c|c|c|c|}
\hline \multirow{2}{*}{\multicolumn{3}{|c|}{$\begin{array}{l}\text { Resultado evaluado respecto del } \\
\text { céneer prostático de acuerdo al } \\
\text { seguimiento }\end{array}$}} & \multicolumn{3}{|c|}{$\begin{array}{l}\text { Grupo rastreo } \\
\text { (n=38.343) }\end{array}$} & \multicolumn{3}{|c|}{$\begin{array}{c}\text { Grupo control } \\
(n=38.350)\end{array}$} & \multirow{2}{*}{$\begin{array}{l}\text { Rate Ratio } \\
\text { (B. } 95 \%)\end{array}$} & \multirow{2}{*}{ I695 } \\
\hline & & & Eventos & AA & Densidad de & Eventos & $\mathrm{RA}$ & Densidad de & & \\
\hline \multirow[t]{3}{*}{ Detección } & Tiempo & $\%$ de seguimiento & & & & & & & & \\
\hline & Siete años & $98 \%$ & 2820 & $7,3 \%$ & & 2322 & $6 \%$ & & $1,22(1,16$ a 1,29$)$ & 74 \\
\hline & Diez años & $67 \%$ & 3452 & $9 \%$ & & 2974 & $7,7 \%$ & & $1,17(1,11$ a 1,22$)$ & 76 \\
\hline \multirow{6}{*}{$\begin{array}{l}\text { Mortalidad por } \\
\text { subgrupo y } \\
\text { según el tiempo } \\
\text { de seguimiento }\end{array}$} & \multicolumn{2}{|c|}{ Siete años } & 50 & 1,3 & 2 & 44 & 1,14 & 1,7 & $1,13(0,75$ a 1,7$)$ & -- \\
\hline & \multicolumn{2}{|c|}{ Diez años } & 92 & 2,3 & 2,7 & 82 & 2,1 & 2,4 & $1,11$ (0,83 a 1,50$)$ & -- \\
\hline & & & \multirow{2}{*}{\multicolumn{3}{|c|}{ Rastreo $(n=34.755)$}} & \multirow{2}{*}{\multicolumn{3}{|c|}{ Control $(n=34.590)$}} & & \\
\hline & & & & & & & & & & \\
\hline & Enrolados luego & Siete años & 48 & & & 41 & & & $1,16(0,76$ a 1,76$)$ & \\
\hline & de $1995^{\circ}$ & Diez años & 83 & & & 75 & & & $1,09(0,80$ a 1,50$)$ & \\
\hline
\end{tabular}

a: Densidad de incidencia: medida en número de eventos (en este caso muertes) cada 10000 personas seguidas durante un año. b: Ajustado por el testeo secuencial del análisis intermedio. c: pacientes con mas de una determinación de PSA basal en los últimos tres años previos al ingreso. NNR: Número de individuos que es necesario rastrear para que ocurra un diagnóstico más que los que se obtendrían si no se efectuara rastreo o para evitar un muerte. RA: riesgo absoluto de eventos.

\section{Conclusión}

Luego de siete a diez años de seguimiento, la tasa de mortalidad por cancer prostático fue muy baja y sin diferencias significatias entre ambos grupos.
Palabras claves: cáncer de próstata, rastreo, ensayo clínico aleatorizado. Keywords: prostate cancer, screening, randomized clinical trial. Fuentes de financiamiento: Nacional Cancer Institute.

Grabriel Villalón [ Servicio de Medicina Familiar y Comunitaria del Hospital Italiano de Buenos Aires. ] PMID: 19297565. Disponible en URL: http://content.nejm.org/cgi/reprint/360/13/1310.pdf 